\title{
ALGUMAS REFLEXÕES SOBRE ENEM, LETRAMENTO E EXCLUSÃO ESCOLAR
}

\author{
SOME REFLECTIONS ON ENEM, LITERACY AND SCHOOL EXCLUSION
}

\author{
OLIVEIRA, Helen Vieira \\ SENNA, Luiz Antônio Gomes
}

\begin{abstract}
RESUMO
0 presente estudo busca realizar uma reflexão acerca das relações transversais entre o Enem, o Letramento e a Exclusão Escolar, tendo como objetivos: a) verificar em que medida o Enem está contemplando os diferentes gêneros textuais na prova de redação; b) discutir suas implicações para os modelos de ensino do letramento do Ensino Médio; c) analisar como tal modelo influencia na exclusão escolar. A discussão está orientada pelas contribuições teóricas de efeito retroativo, letramento, gêneros textuais e exclusão escolar, concentrando-se na análise das últimas nove provas de redação. Concluiu-se que o exame contribui para o ensino de letramento escolar e que não leva em consideração o sujeito e o desenvolvimento de suas habilidades e competências no que se refere às práticas sociais.
\end{abstract}

PaLAVRAS-CHAVE: Letramento; Avaliação Externa; Exclusão Escolar.

\begin{abstract}
This study aims to reflect on the cross-sectional relationships between Enem, Literature and School Exclusion with the following objectives: a) verifying to what extent Enem is contemplating distinct text genres in the written composition exam; b) discuss its implications concerning the teaching models of high school literacy; c) analyze how such a model influences school exclusion. The discussion is guided by the theoretical contributions of retroactive effect, literacy, text genres and school exclusion, concentrating on the analysis of the last nine composition tests. It could be concluded that the exam contributes to the teaching of school literacy and that it does not take into account the subject and the development of his abilities and competences regarding social practices.
\end{abstract}

KeYWORDS: Literacy; External Evaluation; School Exclusion

\section{INTRODUÇÃo}

A educação é um processo que, na maior parte do tempo, observa mais o vir a ser. Esta transitoriedade é muito comum nos estudos e nas práticas relacionadas à infância e à adolescência, o que acaba por não considerar a totalidade do sujeito no 


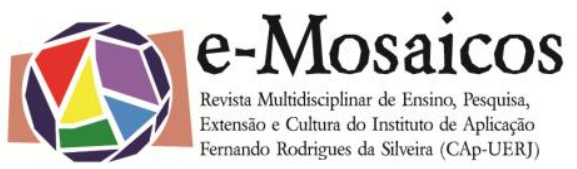

DOI: $10.12957 /$ e-mosaicos.2018.36885

presente. Como afirma Dayrell (p. 41, 2000), "tende-se a negar o presente vivido do jovem como espaço válido de formação, assim como as questões existenciais que eles expõem, bem mais amplas do que apenas o futuro."

Este artigo busca uma análise sobre a forte perspectiva escolar do vir a ser e a avaliação, mais especificamente a avaliação externa da aprendizagem dos alunos, como um mecanismo que solidifica tal concepção. Ou seja, como a busca constante do ensino voltado para as avaliações externas contribuem para uma formação em que não se leva em consideração o sujeito, mas sim o que ele deve ser para a aprovação em tais avaliações. Tal perspectiva pode propiciar um ambiente de exclusão escolar, na medida em que o trabalho é reduzido ao que se é cobrado nas avaliações externas e perde-se a relação com a prática social do conteúdo abordado.

Para isso, será analisada a perspectiva de letramento no Exame Nacional do Ensino Médio, doravante Enem, tendo em vista que é um exame de suma importância para o prosseguimento da vida acadêmica e que apresenta possíveis impactos no Ensino Médio, pois, segundo Anderson e Wall (1993), testes que apresentam consequências importantes terão efeito retroativo. Iremos analisar a proposta de redação do exame desde 2009 até 2017, tendo em vista que a redação vale 1000 pontos, ou seja, $20 \%$ da nota do exame, apresentando, por conseguinte, grande peso na nota fina do aluno.

Para tal fim, este artigo objetiva: a) verificar em que medida o Enem está contemplando os diferentes gêneros textuais na prova de redação; b) discutir suas implicações para os modelos de ensino do letramento do Ensino Médio; c) analisar como tal modelo influencia na exclusão escolar. A discussão está orientada pelas contribuições teóricas de efeito retroativo, letramento e exclusão escolar, concentrando-se nas últimas provas de redação desde 2009. Este artigo fez uma análise apenas das provas de redação, mas entende-se que seria de suma importância realizar uma análise de todos os gêneros empregados nas provas de Linguagem, Códigos e suas Tecnologias, para a verificação do exame como um todo.

Dessa forma, o artigo se divide em quatro seções, das quais a primeira apresenta a questão da avaliação externa das aprendizagens, com foco no Enem; a segunda realiza um diálogo entre o Enem e o efeito retroativo; a terceira traz uma discussão em torno do letramento, a quarta introduz uma análise das provas de redação do Enem à luz do enquadramento teórico sobre gêneros textuais e letramento e, por fim, a quinta seção que apresenta uma reflexão sobre a exclusão escolar sob a perspectiva do letramento no Ensino Médio.

\section{Avaliação Externa: Enem}

A partir dos anos de 1990, no que diz respeito ao Brasil, a discussão sobre avaliação externa da aprendizagem dos alunos começou a ganhar força, muito em decorrência da implantação do Sistema de Avaliação da Educação Básica (Saeb), tendo como objetivo o diagnóstico e a monitoração da qualidade da educação. Em 
e-Mosaicos - Revista Multidisciplinar de Ensino, Pesquisa, Extensão e Cultura do Instituto de Aplicação Fernando Rodrigues da Silveira (CAp-UERJ)

V. 7 - N. 16 - DEZEMBRO 2018 - ISSN: 2316-9303

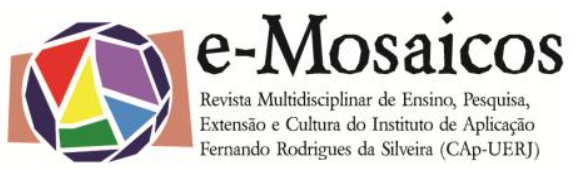

DOI: $10.12957 /$ e-mosaicos.2018.36885

seguida, surge a Prova Brasil em 2005, que apresenta, juntamente com o Saeb, uma política de responsabilização branda (low stakes), pois gera uma consequência simbólica, uma vez que divulga e dissemina os resultados publicamente, gerando assim uma cobrança social por parte dos pais e da comunidade. Em 1998, surge 0 Enem, mas é apenas em 2009, com uma reformulação, que o exame ganha maior peso e passa, dentre outros objetivos, a induzir a reestruturação curricular do Ensino Médio, isto é, "a consagrar o papel do Exame de orientar a melhoria do Ensino Médio em harmonia com os processos de seleção para o acesso à Educação Superior." (BRASIL, 2009, p.1)

No início, em 1998 quando ocorreu o primeiro exame, sua principal finalidade era de proporcionar aos examinados uma autoavaliação, que viria a servir como parâmetro no que se refere à continuidade dos seus estudos ou ao ingresso no mercado de trabalho. Para além desse objetivo, o exame também apresentava: servir de referência para os egressos do Ensino Médio; fornecer subsídios para o acesso à Educação Superior; e servir de acesso aos cursos profissionalizantes pósmédio. (Brasil, 1998)

Uma grande transformação ocorre no exame em 2009, tanto no que diz respeito à composição quanto em seus objetivos. Aos quatro objetivos já citados, 0 Ministério da Educação (MEC) acrescentou mais três, a saber: promover a certificação no nível de conclusão do Ensino Médio; avaliação do desempenho acadêmico dos estudantes ingressantes nas Instituições de Educação Superior; e promover avaliação do desempenho acadêmico das escolas de Ensino Médio. Com esta mudança, o governo busca descentralizar os processos seletivos, para com isso democratizar a participação dos processos seletivos com vagas em diferentes regiões do país. De acordo com Santos (2011), desde a sua primeira edição, o exame busca não apenas uma avalição do diagnóstico do quadro educacional brasileiro, mas também uma avaliação que alcance um diagnóstico individual, possibilitando ao avaliado fazer escolhas a partir de suas competências; e uma avaliação com características complementares, com o intuito de substituir outros exames de admissão. Com isso, de acordo com o autor, o Enem, "já nasce como um projeto de ambição extremamente dilatada." (p. 197)

No entanto, não se alcançou as expectativas do governo com relação ao número de inscritos nos primeiros exames. Em 1998, foram 157.221 inscritos e apenas 2 universidades aceitavam o Enem como forma de ingresso, ou seja, menos de $10 \%$ do total de concluintes do Ensino Médio naquele ano fizeram o exame. A partir do quadro de baixa adesão, o governo passou a redefinir rapidamente a sua estratégia, como afirma Santos (2011), começou então uma popularização do Enem. Uma das estratégias utilizada foi a busca por adesão das universidades públicas, vindo a fortalecer a credibilidade do exame. Com isso, em 10 anos houve um salto significativo do número de inscritos, alcançando o número de 4.004.715 inscritos e cerca de 500 universidades no ano de 2008. O Enem então, através de política de vantagem de possibilidade de acesso à universidade, passa a ser um modelo a ser 
e-Mosaicos - Revista Multidisciplinar de Ensino, Pesquisa, Extensão e Cultura do Instituto de Aplicação Fernando Rodrigues da Silveira (CAp-UERJ)

V. 7 - N. 16 - DEZEMBRO 2018 - ISSN: 2316-9303

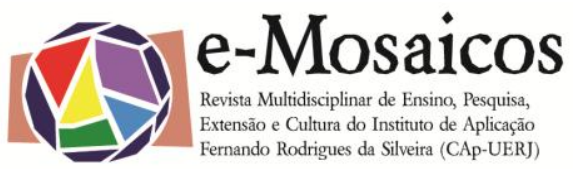

DOI: $10.12957 /$ e-mosaicos.2018.36885

seguido, sem necessariamente impor diretamente sua diretriz. Um novo modelo que busca ocupar o lugar do vestibular, vindo assim a corrigir e orientar o currículo das escolas de Ensino Médio, passando de uma educação voltada de conteúdos para desenvolvimento de competências (Santos, 2011).

\section{Efetto Retroativo do Enem}

De acordo com Scaramucci (2004), entende-se efeito retroativo aqueles gerados pelos mecanismos de avaliação sobre o processo de ensino-aprendizagem, ou seja, impacto ou influência decorrente das avaliações sobre esse processo, em seu produto e também nos seus participantes. Com base em diferentes pesquisas, Cheng (2004, p. 147) afirma que exames, principalmente aqueles que apresentam alta relevância, têm efeitos retroativos no processo de ensino e aprendizagem em diferentes contextos. O autor afirma ainda que os testes de linguagem apresentam um efeito retroativo mais direto no conteúdo do que na metodologia de ensino do professor. Anderson e Wall (1993) fazem uma diferenciação entre efeito retroativo, impacto e influência, na medida em que washback (termo utilizado pelos autores para efeito retroativo) diz respeito aos efeitos dos testes no processo de ensinoaprendizagem; impacto corresponde aos efeitos dos testes nas pessoas, nas escolas, nas políticas, no sistema educacional e na sociedade, e, por fim, as influências como sendo por atitudes de professores e alunos com relação aos testes. Os autores também destacam a predominância na literatura em referir-se aos efeitos negativos, porém eles exploram a potencial relação tanto dos efeitos negativos quanto dos positivos entre os testes e o processo de ensino e aprendizagem. Para este artigo, entenderemos efeito retroativo com base em Scaramucci, ou seja, o efeito retroativo como sinônimo de impacto ou influência.

Apesar de ser um tema relevante para diferentes sujeitos envolvidos com o contexto escolar (Watanabe, 2004) e de, ao longo dos últimos anos, ocorrer um crescente número de publicações sobre o tema, há relativamente poucas pesquisas empíricas nesta área.

Ao realizar uma análise das pesquisas realizadas no contexto brasileiro, notase que há uma predominância de estudos voltados para o efeito retroativo no ensino e na aprendizagem de língua, mais especificamente no campo de língua estrangeira. Scaramucci (2004) faz um levantamento sobre o estado da arte do efeito retroativo da avaliação no ensino/aprendizagem de línguas, apresentando trabalhos concluídos e em andamento na época. Nos últimos anos, como resultado de estudos conduzidos e publicados no Brasil que tomam como base o Enem, pode-se observar algumas pesquisas com o foco na área de Língua. Gomes (2013) busca verificar se o Enem propicia um efeito retroativo nas aulas de Língua Portuguesa; Vicentini (2014) realiza uma análise do efeito retroativo da prova de redação do Enem; Avelar (2015) pesquisa sobre os efeitos das provas de inglês na prática docente; Fernandes (2016) investiga o efeito retroativo dos itens de Espanhol na prática de ensino; Pinheiro e 
DOI: $10.12957 /$ e-mosaicos.2018.36885

Quevedo-Camargo (2017) abordam o efeito retroativo e a teoria de multimodalidade no ensino de leitura, tomando como base as questões de Línguas Estrangeiras do Exame.

O Enem é considerado um exame de grande relevância, tendo em vista que uma de suas características é ser um processo de seleção para o ingresso em diversas universidades, devendo destacar que a maior parte das universidades públicas do país aceita o exame como forma de ingresso. Outra característica que também influencia em sua relevância é a possiblidade de ganhar bolsa ou financiamento em instituições de ensino superior privadas através do Enem. Apesar de haver poucas pesquisas mostrando o efeito retroativo do exame, cabe destacar, como afirmam Pinheiro e Quevedo-Camargo (2017, p.139), "o ENEM tem um potencial transformador, e pode influenciar o currículo, tanto em relação ao conteúdo quanto em relação aos seus pressupostos e suas abordagens." Para Vicentine (2014, p. 2), o exame "tem grande potencial para impactar as práticas de ensino e aprendizagem que o precedem".

\section{LETRAMENTO EsCOLAR}

De acordo com Soares (2004), é em meados de 1980 que surge o termo letramento no Brasil, illetrisme na França, literacia em Portugal, simultaneamente. Tal fato ocorre com o intuito de nomear fenômenos distintos do que então era apenas nomeado de alfabetização, alphabétisation. Por conseguinte, o letramento passa a ser o foco de discussão nas áreas de educação e linguística.

O tema letramento tem gerado amplas discussões e concepções, para Kleiman (1995, p.18), o letramento é "uma prática discursiva de um determinado grupo social, que está relacionada ao papel da escrita para tornar significativa a interação oral, mas que não envolve, necessariamente, as atividades específicas de ler e de escrever". Ou seja, o letramento compreende uma representação ampla, pois estaria envolvido com o uso, função e impacto social da escrita. Magda Soares (1998, p.39), no entanto, compreende o letramento como "resultado da ação de ensinar e aprender as práticas sociais de leitura e escrita; o estado ou condição que adquire um grupo social ou um indivíduo como consequência de ter-se apropriado da escrita e de suas práticas sociais". Isso é, para a autora, o letramento apresenta relação direta com o domínio do sistema convencional da escrita.

Neste artigo, entende-se que o letramento, como objeto de ensino, estaria vinculado à adoção de uma concepção social de escrita, em oposição a uma concepção tradicional, na qual considera a aprendizagem de leitura e da produção textual como a aprendizagem de competência e habilidade individuais. Ou seja, para uma concepção social de escrita, o letramento deve partir de uma concepção de leitura e escrita como práticas discursivas, com um conjunto de práticas relacionadas ao uso, função e impacto social da escrita. (Kleiman, 2007) 
DOI: $10.12957 /$ e-mosaicos.2018.36885

A autora contrasta duas formas de se realizar o letramento em contexto de ensino, a primeira delas seria adotar uma concepção social da escrita, que evidencia uma concepção de leitura e de escrita como práticas discursivas; por outro lado há uma concepção de cunho tradicional, que considera a aprendizagem de leitura e produção textual como a aprendizagem de competências e habilidades individuais, progressivamente desenvolvidas, até chegar a uma competência leitura e escrita ideias, ou seja, o usuário que é proficiente da língua escrita. (2007, p.4)

A partir de uma concepção social da escrita, Kleiman afirma acreditar que a escola é uma "agência de letramento por excelência de nossa sociedade" (2007, p.4), sendo, por conseguinte, de grande importância assumir os múltiplos letramentos como objetivo escolar em todos os anos de escolaridade. No entanto, Cook-Gumperz (1986) afirma que houve uma redefinição de letramento no contexto escolar, vindo a denominar como "letramento escolar", isto é, um trabalho descontextualizado, vindo a ser validado através de desempenho em testes. Soares (1998) também discorre sobre a relação entre letramento e escola, concluindo que o letramento é

Fundamentalmente determinado pelas habilidades e práticas adquiridas através de uma escolarização burocraticamente organizada e traduzidas nos itens de testes e provas de leitura e de escrita. [...] os critérios segundos os quais os testes são construídos é que definem o que é letramento em contextos escolares: um conceito restrito e fortemente controlado, nem sempre condizente com as habilidades de leitura e escrita e as práticas sociais necessárias fora das paredes escolares (p. 85-86)

Com base na concepção de letramento escolar e de efeito retroativo, buscarse-á verificar como se dá a avaliação do letramento no Enem a partir da prova de redação. Esta reflexão se faz relevante na medida em que pode vir a contribuir na compreensão de possíveis efeitos retroativos do exame no Ensino Médio, mais especificamente, como o exame pode vir a influenciar no currículo escolar.

\section{ANÁlise: A RedAÇÃo do Enem e o Letramento Escolar}

Com o objetivo de realizar uma análise da avaliação do letramento que ocorre na redação do Enem, buscou-se investigar como decorreram as práticas letradas nos últimos nove anos de exame - de 2009 até 2017. Optou-se por começar a análise em 2009 por ser o ano de reformulação do exame. Para tal, classificou-se os textos presentes nas propostas com base em Marcushi (2008), identificando-os a partir de seu domínio discursivo e de seus gêneros textuais. Para identificação do gênero dos textos, realizou-se uma análise em seu suporte original, levando em consideração o seu contexto de produção. 
Tabela 1. Domínios Discursivos e Gêneros Discursivos nos Textos Motivadores

\begin{tabular}{|c|c|c|}
\hline Ano & $\begin{array}{l}\text { Domínios } \\
\text { Discursivos }\end{array}$ & Gêneros Discursivos \\
\hline 2009 & $\begin{array}{l}\text { 1- Jornalístico } \\
\text { 2- Jornalístico } \\
\text { 3- Jornalístico }\end{array}$ & 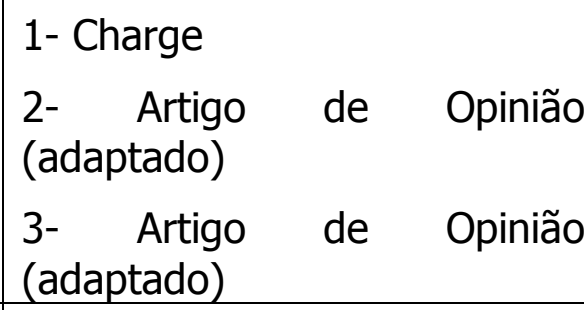 \\
\hline 2010 & $\begin{array}{l}\text { 1- Instrucional } \\
\text { (científico, acadêmico } \\
\text { e educacional) } \\
\text { 2- Jornalístico }\end{array}$ & $\begin{array}{l}\text { 1- Definição (fragmento) } \\
\text { 2- Reportagem (fragmento) }\end{array}$ \\
\hline 2011 & $\begin{array}{l}\text { 1- Jornalístico } \\
\text { 2- Jornalístico } \\
\text { 3- Jornalístico }\end{array}$ & $\begin{array}{lll}\begin{array}{l}\text { 1-Artigo de } \\
\text { (fragmento) }\end{array} & & \text { opinião } \\
\text { 2- Artigo de } & \text { opinião } \\
\text { (adaptado) } & & \\
\text { 3- Charge } & & \\
\end{array}$ \\
\hline 2012 & $\begin{array}{l}\text { 1- Instrucional } \\
\text { (científico, acadêmico } \\
\text { e educacional) } \\
\text { 2- Jornalístico } \\
\text { 3-Instrucional } \\
\text { (científico, acadêmico } \\
\text { e educacional) }\end{array}$ & $\begin{array}{l}\text { 1- Mapa } \\
\text { 2- Reportagem (adaptado) } \\
\text { 3- Artigo Científico (adaptado) }\end{array}$ \\
\hline 2013 & $\begin{array}{l}\text { 1- Político } \\
\text { 2- Publicitário } \\
\text { 3-Instrucional } \\
\text { (científico, acadêmico } \\
\text { e educacional) } \\
\text { 4- Jornalístico }\end{array}$ & $\begin{array}{l}\text { 1- Discurso Político }{ }^{1} \\
\text { 2- Cartaz }{ }^{2} \\
\text { 3- Infográfico }{ }^{3} \text { (adaptado) } \\
\text { 4- Reportagem (adaptado) }\end{array}$ \\
\hline
\end{tabular}

\footnotetext{
${ }^{1}$ Marcushi (2008) não apresenta este gênero, porém acrescentamos a análise.

2 Em sua totalidade, são campanhas de conscientização.

${ }^{3}$ Marchushi (2008) não apresenta o gênero infográfico, apenas gráfico, mas optamos por difwerencias dos dois gêneros textuais.
} 


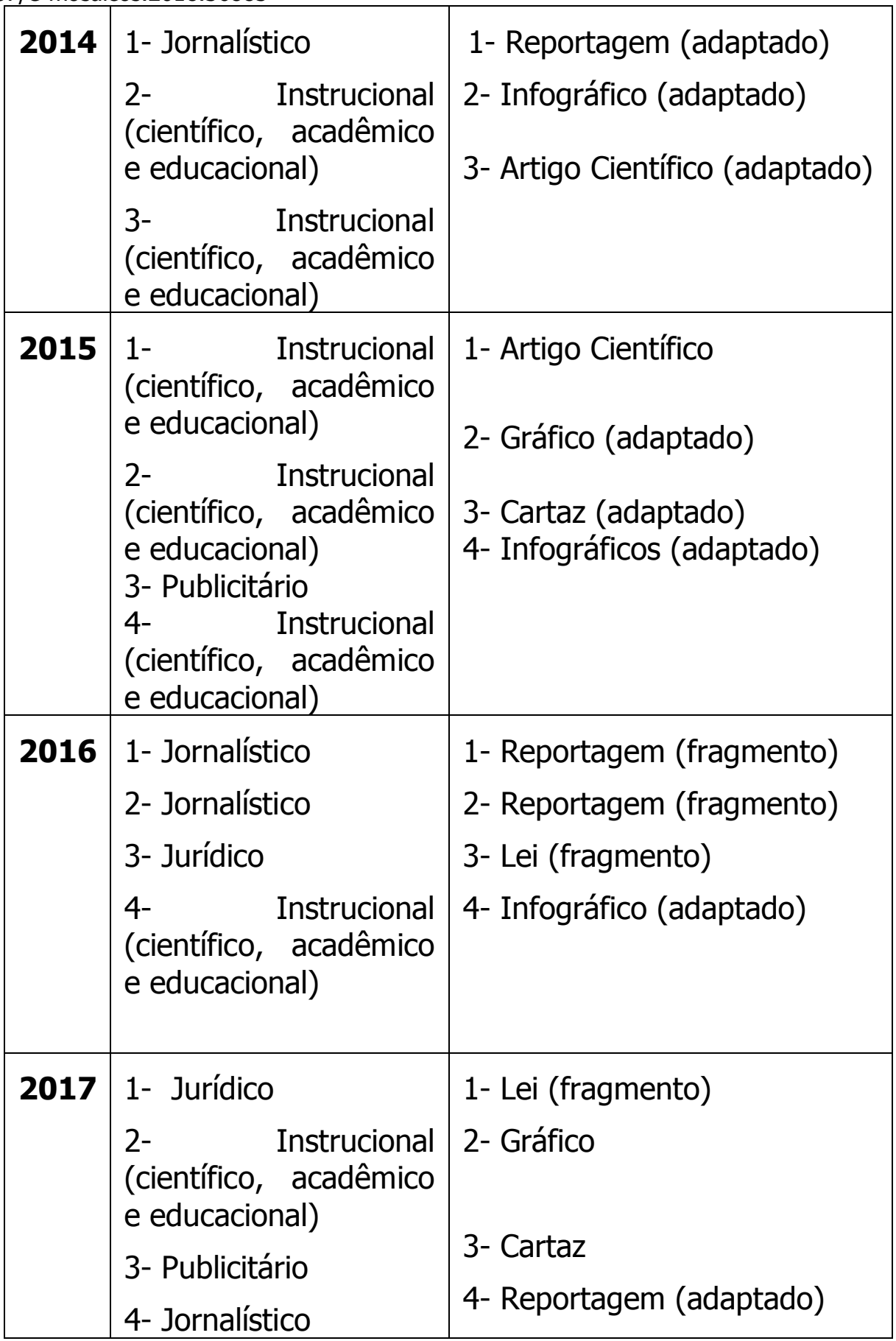

Fonte: Dados obtidos no site do INEP

Tabela 2. Propostas de Redação

\begin{tabular}{|l|l|l|l|}
\hline Ano & Proposta de Redação \\
\hline $\mathbf{2 0 0 9}$ & Com base na leitura dos seguintes textos motivadores e nos \\
\hline
\end{tabular}


DOI: $10.12957 /$ e-mosaicos.2018.36885

\begin{tabular}{|c|c|}
\hline & $\begin{array}{l}\text { conhecimentos construídos ao longo de sua formação, redija texto } \\
\text { dissertativo-argumentativo em norma culta escrita da língua } \\
\text { portuguesa sobre o tema "O indivíduo frente à ética nacional", } \\
\text { apresentando proposta de ação social, que respeite os direitos } \\
\text { humanos. Selecione, organize e relacione coerentemente argumentos } \\
\text { e fatos para defesa do seu ponto de vista. }\end{array}$ \\
\hline 2010 & $\begin{array}{l}\text { Com base na leitura dos seguintes textos motivadores e nos } \\
\text { conhecimentos construídos ao longo de sua formação, redija texto } \\
\text { dissertativo-argumentativo em norma culta escrita da língua } \\
\text { portuguesa sobre o tema "o Trabalho na Construção da } \\
\text { Dignidade Humana", apresentando experiência ou proposta de ação } \\
\text { social, que respeite os direitos humanos. Selecione, organize e } \\
\text { relacione, de forma coerente e coesa, argumentos e fatos para defesa } \\
\text { de seu ponto de vista. }\end{array}$ \\
\hline 2011 & $\begin{array}{l}\text { Com base na leitura dos textos motivadores seguintes e nos } \\
\text { conhecimentos construídos ao longo de sua formação, redija texto } \\
\text { dissertativo-argumentativo em norma padrão da língua portuguesa } \\
\text { sobre o tema "Viver em rede no século XXI: os limites entre o } \\
\text { público e o privado", apresentando proposta de conscientização } \\
\text { social que respeite os direitos humanos. Selecione, organize e } \\
\text { relacione, de forma coerente e coesa, argumentos e fatos para defesa } \\
\text { de seu ponto de vista. }\end{array}$ \\
\hline 2012 & $\begin{array}{l}\text { A partir da leitura dos textos motivadores seguintes e com base nos } \\
\text { conhecimentos construídos ao longo de sua formação, redija texto } \\
\text { dissertativo-argumentativo em norma padrão da língua portuguesa } \\
\text { sobre o tema "O movimento imigratório para o brasil no século } \\
\text { XXI", apresentando proposta de intervenção, que respeite os direitos } \\
\text { humanos. Selecione, organize e relacione, de forma coerente e coesa, } \\
\text { argumentos e fatos para defesa de seu ponto de vista. }\end{array}$ \\
\hline 2013 & $\begin{array}{l}\text { A partir da leitura dos textos motivadores seguintes e com base nos } \\
\text { conhecimentos construídos ao longo de sua formação, redija texto } \\
\text { dissertativo-argumentativo na modalidade escrita formal da língua } \\
\text { portuguesa sobre o tema "Efeitos da implantação da Lei Seca no } \\
\text { Brasil", apresentando proposta de intervenção, que respeite os } \\
\text { direitos humanos. Selecione, organize e relacione, de forma coerente e } \\
\text { coesa, argumentos e fatos para defesa de seu ponto de vista }\end{array}$ \\
\hline 2014 & $\begin{array}{l}\text { A partir da leitura dos textos motivadores seguintes e com base nos } \\
\text { conhecimentos construídos ao longo de sua formação, redija texto } \\
\text { dissertativo-argumentativo em norma padrão da língua portuguesa } \\
\text { sobre o tema "Publicidade infantil em questão no Brasil", } \\
\text { apresentando proposta de intervenção, que respeite os direitos } \\
\text { humanos. Selecione, organize e relacione, de forma coerente e coesa, } \\
\text { argumentos e fatos para defesa de seu ponto de vista. }\end{array}$ \\
\hline
\end{tabular}


DOI: $10.12957 /$ e-mosaicos.2018.36885

\begin{tabular}{|c|c|}
\hline 2015 & $\begin{array}{l}\text { A partir da leitura dos textos motivadores seguintes e com base nos } \\
\text { conhecimentos construídos ao longo de sua formação, redija texto } \\
\text { dissertativo-argumentativo em modalidade escrita formal da língua } \\
\text { portuguesa sobre o tema "A persistência da violência contra a } \\
\text { mulher na sociedade brasileira", apresentando proposta de } \\
\text { intervenção que respeite os direitos humanos. Selecione, organize e } \\
\text { relacione, de forma coerente e coesa, argumentos e fatos para defesa } \\
\text { de seu ponto de vista. }\end{array}$ \\
\hline 2016 & $\begin{array}{l}\text { A partir da leitura dos textos motivadores e com base nos } \\
\text { conhecimentos construídos ao longo de sua formação, redija texto } \\
\text { dissertativo-argumentativo em modalidade escrita formal da língua } \\
\text { portuguesa sobre o tema "Caminhos para combater a } \\
\text { intolerância religiosa no Brasil", apresentando proposta de } \\
\text { intervenção que respeite os direitos humanos. Selecione, organize e } \\
\text { relacione, de forma coerente e coesa, argumentos e fatos para defesa } \\
\text { de seu ponto de vista. }\end{array}$ \\
\hline 17 & $\begin{array}{l}\text { A partir da leitura dos textos motivadores e com base nos } \\
\text { conhecimentos construídos ao longo de sua formação, redija texto } \\
\text { dissertativo-argumentativo em modalidade escrita formal da língua } \\
\text { portuguesa sobre o tema "Desafios para a formação educacional } \\
\text { de surdos no Brasil", apresentando proposta de intervenção que } \\
\text { respeite os direitos humanos. Selecione, organize e relacione, de forma } \\
\text { coerente e coesa, argumentos e fatos para defesa de seu ponto de }\end{array}$ \\
\hline
\end{tabular}

Fonte: Dados obtidos no site do INEP

Ao longo dos anos analisados, as provas de redação apresentaram de 3 a 4 textos motivadores, a maior parte dos textos foi adaptado ou fragmentado. Fica evidente que há uma recorrência dos mesmos gêneros textuais, tendo em vista que, dos 30 textos analisados, 33,3\% são artigos (opinião e científico), 23,3\% são reportagens e $16,6 \%$ são gráfcos/infográficos. Em relação ao texto pedido para a produção da proposta de redação, o texto dissertativo-argumentativo se solidificou como o texto do gênero prova de vestibular (Marcushi, 2008) presente em todas as edições analisadas.

A recorrência dos mesmos gêneros na prova de redação pode reduz imensamente o trabalho escolar com a diversidade de textos que circulam na sociedade. Verifica-se que não há uma preocupação de diversificação de gêneros para a produção da redação, tanto no que se refere à leitura dos textos motivadores quanto à produção do texto. O enfoque da redação do Enem acaba por reduzir o letramento, como afirma Soares (2010, p. 86), "o fenômeno complexo e multifacetado do letramento é reduzido àquelas habilidades de leitura e escrita e àqueles usos sociais que os testes avaliam e medem.". 
DOI: $10.12957 /$ e-mosaicos.2018.36885

Ao levar em consideração tal redução dos gêneros na prova de redação do Enem, observa-se que o exame pode condicionar a uma prática voltada mais para uma concepção de letramento tradicional, no qual a aprendizagem de leitura e de produção textual estariam mais voltadas para competências e habilidades individuais. Em detrimento de uma concepção social, no qual há uma relação entre as práticas discursivas e o seu uso, função e impacto social.

No relatório nacional do Pisa 2015 realizado pelo Inep, há um capítulo que realiza uma análise comparada entre os componentes do construto do teste do Pisa e as matrizes de referência do Sistema de Avaliação da Educação Básica - Saeb. Com respeito à leitura, o documento conclui que o Pisa realiza avaliações que consideram a participação ativa do leitor durante todo o processo de leitura, através de textos pertencentes às experiências pessoais e seu conhecimento de mundo, tal questão foge ao Saeb, tendo em vista que nessa avaliação há um predomínio de gêneros pertencentes às esferas literária e jornalística. Bonamino et al. (2002), em pesquisa realizada sobre avaliação e letramento, chega a afirmar que

apesar de trazer dados valiosos a respeito das habilidades de leitura dos alunos brasileiros, não verifica diretamente a capacidade de leitura (e consequentemente o grau de letramento) desses estudantes, uma vez que a habilidade deles de lidar com vários textos do cotidiano não é diretamente verificada no SAEB. (p. 93).

Este fato não se restringe apenas ao Saeb, ao analisar as provas de redação dos últimos anos do Enem, observa-se o mesmo movimento, a restrição dos gêneros dos textos motivadores e da proposta da redação. O que acaba por não avaliar verdadeiramente o grau de letramento dos alunos, mas também pode vir a gerar um efeito de se trabalhar mais com os gêneros presentes no exame na escola, realizando assim, como afirma Cook-Gumperz (1986), um letramento escolar no Ensino Médio.

Ao analisar as propostas de redação do Enem, podemos notar que há uma preocupação em auxiliar ao aluno na produção do texto, na medida em que apresenta os textos motivadores, o que favorece a uma análise entre diferentes gêneros e seus usos sociais. A solicitação para uma proposta de intervenção que respeite os diretos humanos também é algo positivo na prova, tendo em vista que busca uma prática social na escrita. Porém, ao reduzir a diversidade dos gêneros apresentados nos textos motivadores e definir apenas um gênero para a sua questão discursiva, o exame acaba por realizar uma avaliação em que o letramento está voltado para a prática escolar, perdendo o seu real sentido social.

\section{O Processo de Exclusão sob a Perspectiva do letramento no Ensino MÉDIO}


DOI: $10.12957 /$ e-mosaicos.2018.36885

Várias questões podem ser consideradas a partir dessa redução do letramento para um letramento escolar, uma delas é a exclusão escolar. Por muito tempo, foi-se necessário considerar exclusão, no campo escolar, olhando pelo prisma dos que estavam fora da escola. Muito se trabalhou para conseguir acesso a todos. Hoje podemos e devemos lançar luz sobre as diferentes formas de exclusão dentro do sistema formal de ensino, como afirma Barroso (2003, p. 27) a escola exclui porque não deixa entrar os que estão fora; porque põe fora os que estão dentro; exclui "incluindo"; e porque a inclusão deixou de fazer sentido.

Neste trabalho, destacamos a terceira modalidade mencionada pelo autor. Como afirma "No caso da 'exclusão pela inclusão', o que está em causa, sobretudo, é a imposição de modelos de organização pedagógica e padrões culturais uniformes" (Barroso, 2003, p. 27). O fato de os alunos terem acesso à escola, não garante a sua inclusão no sistema educacional. Práticas curriculares, concepções pedagógicas, atitudes dos docentes levam à exclusão de alunos "incluídos" na escola, ou seja, exclui aqueles que estão dentro da escola. Assim, ela corrobora com a exclusão já existente na sociedade.

No sistema educacional brasileiro, se observa um funil (Santos, 2011), muitos entram, poucos saem, ao longo dos anos, o baixo rendimento, a evasão e a repetência contribuem para selecionar os que sairão. Mas 0 fato de concluir a Educação Básica também não garante uma verdadeira formação, não garante que este aluno foi incluído no processo. Como afirma Senna (2008)

A superação da exclusão escolar demanda, no entanto, muito mais do que mero direito a vaga e permanência; demanda a superação dos valores que segregam e banem o indivíduo no cotidiano de uma experiência em que jamais conseguem superar os limites do intolerável, do fracasso eminente. (p. 202)

Os alunos que conseguem passar pela alfabetização e primeiros anos da escolaridade, mas que, no entanto, são considerados confusos, são alunos que com muito custo permanecem na escola, mas que não dominam os mecanismos mentais tidos científicos presente nesse espaço. O Enem, como uma avaliação nacional de efeito retroativo, acaba por contribuir com essa exclusão. Exclui não apenas no que tange ao não acesso à universidade, mas exclui no próprio espaço escolar, quando opta em seu letramento uma linha em que não verifica a habilidade dos alunos em lidar com vários textos do cotidiano, mas sim restringe a um número reduzido de gênero textuais, trabalha com uma concepção de letramento escolar. Excluir também na medida em que aumenta a desigualdade no âmbito intraescolar, pois as escolas acabam por investir mais nos melhores alunos, ou seja, aqueles que apresentam potencialidade em passar no exame (FERNANDES, 2008; OLIVEIRA et al, 2013), podendo assim, haver uma discriminação, no lugar na integração, principalmente no 


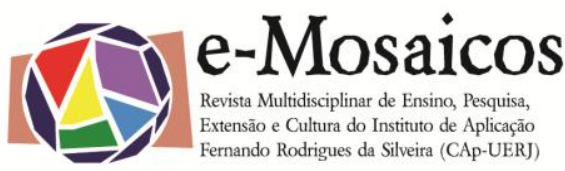

DOI: $10.12957 /$ e-mosaicos.2018.36885

que tange a certos grupos pertencentes a minorias de qualquer natureza (FERNANDES, 2008, p.116)

Neste cenário, vemos alunos que em um primeiro momento conseguem empregar o modo científico de pensamento na aquisição dos códigos da escrita, porém não continua a desenvolvê-lo no que tange à produção textual, o que se esperaria de um sujeito cognoscente, um crescente no modo de pensamento científico. Tal fato acaba por não ser previsto pelo docente, que não sabe como lidar com tal situação, vindo a considerar o aluno como fora da normatividade do pensamento acadêmico, isto é, um sujeito deficiente. "Sujeitos não assimiláveis pela normalidade da razão moderna simplesmente não existem como possibilidade de sujeitos que aprendem na literatura que forma o professor" (Senna, 2008, p. 202), sendo excluídos mesmo estando presentes no sistema escolar. Fatores externos podem corroborar com essa exclusão, o Enem seria um deles, tendo em vista seu potencial para o efeito retroativo na Educação Básica.

\section{CONSIDERAÇÕES FinAIS}

É de suma importância que haja uma maior reflexão sobre qual a relação entre o Enem e o letramento dos alunos do Ensino Médio, tendo em vista que "o ENEM tem um potencial transformador, e pode influenciar o currículo, tanto em relação ao conteúdo quanto em relação aos seus pressupostos e suas abordagens." (Pinheiro e Quevedo-Camargo, 2017, p.139). Como analisado, observou-se nos últimos nove anos que no exame, no que se refere à prova de redação, há uma predominância de gêneros dos domínios instrucional e jornalístico, o que reduz o trabalho com habilidades em lidar com diversidade discursiva do cotidiano, reduzindo assim a um letramento escolar.

Tal redução no letramento acaba, por conseguinte, acentuando o fracasso dos alunos que não conseguiram avançar no desenvolvimento do pensamento narrativo para o pensamento científico. Tal fato, propicia para a exclusão desses alunos, que mesmo dentro da escola e muitas vezes conseguindo concluir a Educação Básica, acabam por não desenvolver por completo suas habilidades em leitura e escrita, tendo em vista que Ihes é cobrado um letramento que não corresponde com textos pertencentes às experiências pessoais e seu conhecimento de mundo, ou seja, seu desenvolvimento fica restrito a um letramento que não evidencia uma concepção de leitura e escrita como práticas discursivas, com um conjunto de práticas relacionadas ao uso, função e impacto social da escrita. (Kleiman, 2007). 


\section{Referências}

ALDERSON, J.; WALL, D. Does Washback Exist?. Applied Linguistics, 14(2), 115129, 1993.

AVELAR, F.J.S. O inglês no ENEM e na escola: práticas de dois professores do ensino médio. Campinas, SP. Tese de doutorado. Universidade Estadual de Campinas, 272 p., 2015.

BARROSO, J. Fatores organizacionais da exclusão escolar: a inclusão exclusiva. In: RODRIGUES, David (org.). Perspectivas sobre a inclusão: da educação à sociedade. Porto: Editora Porto, 2003.

BRASIL. Ministério da Educação. Portaria MEC 438, de 28 de maio de 1998. Institui o Exame Nacional do Ensino Médio. Brasília, DF, 1998.

BRASIL. Ministério da Educação. Matriz de Referência para o ENEM. Brasília: MEC/INEP, 2009.

BONAMINO, A.; COSCARELLI, C.; FRANCO, C. Avaliação e letramento: concepções de aluno letradosubjacentes ao SAEB e ao PISA. Educação \& Sociedade, 23(81), 2002.

COOK-GUMPERZ, J. Literacy and schooling: An unchanging equation. The social construction of literacy, p. 16-44, 1986.

CHENG, L. The Washback Effect of a Public Examination Change on Teachers' Perceptions Toward Their Classroom Teaching. In L. Cheng, Y. Watanabe, \& A. Curtis, (eds) Washback in language testing: Research contexts and methods. Mahwah, NJ: Lawrence Erlbaum Associates, 2004.

DAYRELL, J. 0 jovem como sujeito social. Revista Brasileira de Educação, Rio de Janeiro: ANPEd, Campinas: Autores Associados, n² 24, set.-dez., p. 40-52, 2003.

FERNANDES, D. Avaliação das aprendizagens: desafios às teorias, práticas e políticas. Lisboa: Texto Editores, 2005.

FERNANDES, P. S. R. Os itens de espanhol do Enem: em busca de efeito(s) retroativo(s) na prática do professor em serviço. 2016. 185 f., il. Dissertação (Mestrado em Linguística Aplicada)-Universidade de Brasília, Brasília, 2016.

GOMES, L. L. Z. O "novo" Exame Nacional do Ensino Médio: em busca de indícios de efeito retroativo no ensino de Língua Portuguesa. 2013. 202 f. 
DOI: $10.12957 /$ e-mosaicos.2018.36885

2013. Tese de Doutorado. Dissertação (Mestrado em Estudos Linguísticos) Universidade Federal de Uberlândia, Uberlândia.

KLEIMAN, A. B. (Org.). Os significados do letramento: uma nova perspectiva sobre a prática social da escrita. Campinas, S.P.: Mercado de Letras, Coleção Letramento, Educação e Sociedade, 1995.

KLEIMAN, A. B. Letramento e suas implicações para o ensino de Língua Materna. Revista Signo. Santa Cruz do Sul, v. 32 n 53, p. 1-25, dez, 2007.

MARCUSCHI, L. A. Produção textual, análise de gêneros e compreensão. Parábola Ed., 2009.

OLIVEIRA, R. et al. Análise das desigualdades intraescolares no Brasil. Estudos e Pesquisas Educacionais, v.4, 2013.

PINHEIRO, L. L. S.; QUEVEDO-CAMARGO, G. Efeito retroativo e multimodalidade no ENEM: análise de questões de inglês e espanhol. Signum: Estudos da Linguagem, v. 20, n. 1, p. 136-166, 2017.

SANTOS, J. M. C. T. Exame Nacional do Ensino Médio: entre a regulação da qualidade do Ensino Médio e o vestibular. Educar em revista, v. 27, n. 40, p. 195-205, 2011.

SCARAMUCCI, M. V.R. Efeito retroativo da avaliação no ensino/aprendizagem de línguas: 0 estado da arte. Trabalho em Linguística Aplicada, 43(2), 203-226, 2004.

SENNA, L. A. G. Formação docente e educação inclusiva. Cadernos de pesquisa, 38(133), 195-219, 2008.

SOARES, M. Letramento e alfabetização: as muitas facetas. Revista Brasileira de Educação, Rio de Janeiro, n.25, Abr, 2004.

SOARES, M. Letramento: um tema em três gêneros. Belo Horizonte: Autêntica, 1998.

VICENTINI, M. P. A proposta de redação do Enem e seu possível efeito retroativo negativo no Ensino Médio. In. Anais do Enelin 2013, p. 433-438, 2014.

WATANABE, Y. Methodology in Washback Studies. In L. Cheng, Y. Watanabe, \& A. Curtis, (eds) Washback in language testing: Research contexts and methods. Mahwah, NJ: Lawrence Erlbaum Associates, 2004.

Recebido em 26 de agosto de 2018 
e-Mosaicos - Revista Multidisciplinar de Ensino, Pesquisa, Extensão e Cultura do Instituto de Aplicação Fernando Rodrigues da Silveira (CAp-UERJ)

V. 7 - N. 16 - DEZEMBRO 2018 - ISSN: 2316-9303 